\title{
UMA INFÂNCIA, UM SILÊNCIO, UM APRENDIZADO DO GESTO
}

\author{
Cintya Regina Ribeiro ${ }^{1}$ \\ Universidade de São Paulo, Brasil
}

\begin{abstract}
Resumo
Incêndios, peça teatral escrita pelo libanês Wadji Mouawad e publicada em francês em 2003, sugere, a partir da singularidade de uma condição histórico-familiar, uma incursão analítica nas questões que remetem às relações entre gestualidade, ética, política e infância. A análise elege dois momentos da obra teatral para conduzir a argumentação: a) os efeitos do gesto de silêncio da personagem Nawal; b) a conclamação ao gesto de escrita que perpassa as três gerações de mulheres. $\mathrm{O}$ ensaio organiza-se a partir de três planos analíticos. Num primeiro, a partir da questão do silêncio do gesto, buscamos, na companhia de Giorgio Agamben, explorar as relações entre politização e estilização da gestualidade. Em seguida, no horizonte do pensamento de Gilles Deleuze e Félix Guattari, buscamos tomar a dimensão do gesto como recurso estratégico, da ordem dos signos, na produção de cartografias do viver. Argumentamos que as urgências cartográficas constituem-se como trabalhos de estilização e politização das formas de vida, demandando uma articulação entre política da atenção e gestualidade. Num terceiro movimento, o trabalho busca aproximar a questão da gestualidade numa perspectiva de aprendizado, apontando os efeitos dessa experiência para tomarmos infância como uma força pervasiva capaz de ubiquidade num tempo qualquer e em toda parte. A análise conclui sobre o caráter de impessoalidade do gesto e de sua respectiva potência como assinatura do mundo.
\end{abstract}

Palavras-chave: gesto; estilização; cartografia; infância; política da atenção

\section{A childhood, a silence, a learning gesture}

\section{Abstract}

Scorched, a play written by the Lebanese dramatist Wadji Mouawad and published in French in 2003, suggests, beyond the singularity of a historical family context, an investigation about the relationship between gestures, ethics, politics and childhood. The analysis sets out two moments of the narrative to develop the discussions: a) the effects of the silence of Nawal's character; b) the writing gesture that runs through the three generations of women. The paper is, therefore, organized according to three analytical levels. At first, regarding the gesture of silence, it explores the relationship between politicization and stylization, along with Giorgio Agamben's theoretical inspiration; secondly, following Gilles Deleuze and Felix Guattari's theoretical legacy, the paper examines the relationship between gesture and signs, in order to present a cartographic production of living. We state that the cartographic urgencies constitute a kind of labor of stylization and politicization of life forms, which requires an articulation between gestures and a political attention. Finally, the analysis approaches the issue of gestures in a learning perspective, pointing out the effects of such experience in order to understand childhood as a pervasive force capable of ubiquity anytime and anywhere. The paper concludes affirming the impersonality nature of gesture and its potency as a signature in the world.

Key-words: gesture; stylization; cartography; childhood; political attention

${ }^{1}$ E-mail: cintyaribeiro@usp.br 


\section{Una niñez, un silencio, un aprendizaje del gesto}

\section{Resumen}

Incendios, obra escrita por el libanés Wadji Mouawad y publicada en francés en 2003, sugiere, desde la singularidad de una situación familiar histórica, una incursión analítica sobre cuestiones que se refieren a la relación entre gestualidad, ética, política e infancia. El análisis elige dos momentos de la obra para argumentar: a) los efectos del gesto de silencio del personaje Nawal; b) la llamada al gesto de escritura que se ejecuta a través de las tres generaciones de mujeres. El artículo se organiza a partir de tres ejes de análisis. En un primer momento, desde la pregunta acerca del silencio del gesto, buscamos, en compañía de Giorgio Agamben, explorar la relación entre la politización y la estilización de los gestos. A continuación, en el horizonte del pensamiento de Gilles Deleuze y Félix Guattari, buscamos tomar el alcance del gesto como un recurso estratégico, en el orden de los signos, en la producción de cartografías de la vida. Se argumenta que las emergencias cartográficas constituyen obras de estilización y politización de las formas de vida, lo que requiere un vínculo entre la política de la atención y la gestualidad. En el tercer movimiento, el análisis trata de abordar el tema de la gestualidad en una perspectiva de aprendizaje, señalando los efectos de esta experiencia para tomar a la infancia como una fuerza omnipresente capaz de ubicuidad en cualquier momento y en todo lugar. El análisis concluye con la impersonalidad del gesto y su respectivo poder como una firma del mundo.

Palabras clave: gesto; estilización; cartografía; infancia; política de la atención 
UMA INFÂNCIA, UM SILÊNCIO, UM APRENDIZADO DO GESTO

Jamais o gesto do pintor fica na moldura, ele sai da moldura e não começa com ela.

G. Deleuze; F. Guattari (1992, p.242)

Há um excessivo ruído no mundo. Com velocidades díspares, sons sobrepostos concorrem. O século arrasta consigo essa extensa genealogia do indizível. Sensível a essa confluência de sons incógnitos, Wajdi Mouawad (2013), a partir da espessura de sua obra teatral Incêndios, parece evocar tal horizonte de experiências cujos efeitos remetem de modo incisivo aos nossos atuais dilemas ético-políticos.

Incêndios (MOUAWAD, 2013) narra uma epopeia familiar contemporânea, num contexto geopolítico de guerras étnico-culturais. Uma mulher, um filho que lhe foi subtraído no nascimento. As rotas de fuga das populações ameaçadas trataram de separá-los. Insuspeitas veredas cuidaram de colocá-los frente a frente, num tempo outro, em arenas políticas opostas, como adversários de ódio, alheios, ambos, às condições de origem que os vinculam biologicamente. Do estupro cultural e político, nasce um casal de filhos, gêmeos. Outros itinerários cuidarão agora de sufocar a memória dessa genealogia trágica, arremessando cada um à suposta liberdade subjetiva de uma vida autônoma no presente do século XXI, tal como apregoa a crença dogmática constitutiva de certo modo contemporâneo de viver.

É dessa ambiência que buscamos fazer irromper o veio argumentativo de nosso ensaio de pensamento. Aqui, não importa uma dedicação reflexiva ao desfecho dessa narrativa, a saber, a partilha de um conhecimento, entre todos, a propósito dessa verdade trágica que singularmente os produz.

Interessa-nos explorar outro timing dessa experiência: a emergência de uma temporalidade intensiva que, refratária à clássica obediência à linearidade temporal da narrativa - com suas demandas de começos, meios e fins - se instala 
compulsoriamente, ativando outra pergunta, exigindo outro modo de endereçamento à vida.

Propomos espreitar analiticamente esse movimento a partir da mirada do gesto. É num dos filhos gêmeos da personagem Nawal, a jovem estudante de matemática Jeanne, que focalizaremos nosso olhar.

Retomemos, pois, a atmosfera dos ruídos do mundo. Mouawad (2013) nos traz, de largada, a personagem Nawal capturada por uma experiência de enigmático e abissal silêncio. Trata-se de um silêncio afirmativo, porém, intransitivo; um gesto radical de ocupação do presente, invadindo sua orquestração ruidosa, colocando-o em absoluta suspensão, espraiando-se à moda de um pathos de época.

Não se trata, entretanto de um ato subjetivado, ou seja, manifestação expressiva de uma suposta subjetividade originária. Materialidade permeável, Nawal dá passagem às forças contingenciais do fluxo do tempo e seu corpopensamento "acontece" como ocasião de uma miríade de signos indevassáveis. Arrastada por tais fluxos, ainda que em condição de resistência, Jeanne, linha singular de passagem, afirma esse encontro com o incognoscível.

Diríamos que as figuras dos gêmeos Simon e Jeanne acionariam movimentos variados, com seus efeitos específicos. Mas é Jeanne uma espécie de linha de passagem que estrategicamente buscamos acompanhar - é de seu encontro com o acontecimento do silenciar que se criarão outros mundos.

Ardiloso é o jogo do silêncio, para o qual se exige certa diligência à iniciação. Respira-se sob o fio da navalha. O ruído do mundo pode calar o silêncio, quando, de modo reativo, anula-se a potência do vácuo aí instalado, olvidando-o, abstraindo-o, refratando-o, enfim. Mas, esse jogo pode transgredir-se, num golpe de coragem: esse ruído do mundo pode também fazer silenciar: nesse caso, numa ocupação performática do silêncio, a vacuidade sonora se afirma, expandindo-se como uma força disruptiva vital a fecundar o presente, abrindo-lhe sua temporalidade intensiva. 
Assim, não nos interessa tomar a localidade hermenêutica do gesto de silêncio de Nawal, a mãe. Interessa-nos perseguir os efeitos-silêncio potencializados nessa linha de passagem, Nawal-Jeanne, flagrando as próprias condições desse gesto de silenciar, em sua expansão dançarina, de tal modo que possamos fazer uma imersão oceânica na própria experiência de silêncio imanente ao encontro dessas vidas.

É nesse sentido que gesto será aqui apreendido analiticamente como experiência impessoal, refratária a quaisquer prerrogativas de filosofias do sujeito. Trata-se, pois, de capturar certas ocasiões de culminância de uma vida. Desse modo, diríamos que é a vida mesma que silencia e, nesse seu gesto, convoca a outras destinações.

\section{Das intransitividades moventes}

Poderíamos falar, pois, de uma política dos gestos, cuja especificidade será talhada no decorrer de nossas digressões. Se, aqui, gestualidade não remete ao jugo subjetivo, identitário, faz-se necessário operá-la como um efeito da própria materialidade dos encontros.

Jean Galard (1997), em seu ensaio A beleza do gesto, busca, a partir de uma discussão sobre uma estética das condutas, problematizar o fundamento ontológico do sujeito da expressão bem como o caráter de subjetivação presumido na gestualidade, princípios estes particularmente sustentados pela tradição estética do romantismo.

Recusando-se a tomar os processos de estilização das condutas a partir de princípios universais transcendentes, o ensaísta indaga: “Será que não se pode imaginar, em vez de leis que se supõem governando a vida moral, uma arte do 'pertinente', produzindo para cada situação singular o gesto que a convém?" (GALARD, 1997, p, 17).

A interpelação é oportuna para erodirmos uma suposta sacralização do gesto - artifício que lhe conferiria uma natureza transcendente ou sublime - e ao mesmo tempo dilatarmos o campo de possibilidades - tanto analíticas quando 
uma infância, um silêncio, um aprendizado do gesto

ético-políticas - quando lançamos essa experiência do gesto à sua condição de imanência.

Tal autor defende a tese de que o franqueamento do gesto estaria vinculado a uma dispersão subjetiva, ou seja, à marcação de uma distância ou de um recuo em relação a si mesmo, em detrimento de um trabalho de encontro com uma suposta verdade subjetiva, identitária. Para sustentar sua argumentação, busca evocar, a partir dos territórios da arte, possíveis articulações para pensarmos uma arte ou estética das condutas - daí a sagacidade dessa ênfase numa discussão que problematiza as teorizações tradicionais sobre gesto. De acordo com sua análise:

É próprio da arte em geral tornar-se acolhedora dos achados fortuitos. Tirar partido dos materiais é, ao mesmo tempo, deixar viver seus acidentes. [...] Ora, é próprio da arte de viver lidar com o acontecimento, em outras palavras, com o imponderável e o imprevisível. (GALARD, 1997, p.100)

Essa abordagem das artes como um trabalho de luta com a materialidade seja no talhar o acidental dos materiais ou no afirmar radical do acaso do viver será o vórtice a partir do qual o gesto escapará de qualquer mandamento subjetivante. Para lidar com o imponderável dos materiais ou da vida, faz-se necessário um trabalho de desfocalização. Mais especificamente, "o efeito da desfocalização equivaleria a dissociar os gestos do sujeito que os realiza, a tomá-los pelo que dizem ou pelo que fazem, sem os imputar a uma substância subjetiva" (GALARD, 1997, p. 103).

Aqui, desfocalização remete a uma espécie de flutuação da atenção, a um deslocar-se andarilho, arredio à seriação linear dos eventos e ao mesmo tempo atiçado pelos chamamentos da viagem.

Nesse sentido o gesto encontra sua virtual potência na medida mesma em que se afasta dos cálculos de subjetivação, do logos, da doxa, vertendo-se, assim, como uma inundação estrangeira. A desfocalização ativa um jogo de exterioridade, uma vez que "destitui o essencial, dá sentido ao acidental, detém-se no detalhe, deriva na margem" (GALARD, 1997, p.90).

Assim, defendemos que essa decalagem entre sacralização subjetivoidentitária e mundanidade de experiências de encontros constitui aquilo mesmo 
que anima o gesto numa potência do impessoal. A propósito do efeito de criação desdobrado desse movimento, Galard (1997) nos lembra que "quando [os artistas da conduta] se retiram, o gesto inteiro de sua vida tem a densidade de uma obra" (p. 117).

Gesto e obra se confundem, portanto, como um só trabalho, performativo, de estilização e politização da vida. Afirmamos, portanto, que habitar esses movimentos incorpóreos do gesto - "atenção flutuante, visão sem foco, vigilância esparsa" (GALARD, 1997, p. 101) - exige recusar a loquacidade do mundo e ao mesmo tempo nele se imiscuir, numa travessia muda.

No esteio dessas discussões, poderíamos inferir duas formulações cruciais à argumentação desse trabalho: em primeiro lugar, assumimos a ideia de que dessubjetivar o gesto torna-se, pois, uma ética e uma política; em segundo lugar, postulamos que, uma vez imantado num campo ético-político, todo gesto sustentase em certa política do silêncio, a qual por sua vez, demanda certa política da atenção.

Conduzindo uma instigante digressão a respeito do gesto, Giorgio Agamben (2008) nos lança a um território de sutilezas, para explorarmos tal incursão analítica. Em seu ensaio Notas sobre o gesto, o pensador italiano cunha a seguinte imagem: “O que caracteriza o gesto é que, nele, não se produz, nem se age, mas se assume e suporta. Isto é, o gesto abre a esfera do ethos como esfera mais própria do homem" (AGAMBEN, 2008, p. 13).

Considerando discussões aristotélicas, o autor contemporâneo articula as singularidades de três gêneros referentes à ação: afirma a distinção entre as categorias do fazer e do agir, distinguindo, de ambas, a noção de gesto. Enquanto o fazer estaria endereçado a um fim que lhe é exterior, o agir remeteria à própria ação em si, constituindo-se, pois, como uma finalidade em si mesma. Ambos se constituem como meios consagrados a um fim, ainda que voltados a qualidades distintas. Diferentemente, o gesto seria de outro matiz: nem um fazer, nem um agir - um suportar, um sustentar, um suster, um assumir. 
Em resumo, o fazer seria um meio em vista de um fim; o agir seria um fim sem meios. O gesto seria a pura exposição de um meio em si mesmo, sem remissão a um fim - "um meio sem fim", nos termos de Agamben. Sua evocação é impecável:

Se a dança é gesto, é porque, ao contrário, esta é somente o suportar e a exibição do caráter medial dos movimentos corporais. O gesto é a exibição de uma medialidade, o tornar visivel um meio como tal. (AGAMBEN, 2008, p. 13 , grifos do autor)

Nessa imagem, gesto se constitui como o próprio movimento de sustentação, expondo-se em condição de potência, como pura medialidade, ou seja, como meio em si mesmo. Em outras palavras, aquilo que o gesto comunica é seu ato mesmo de sustentação. Nos termos de Agamben (2008, p.13), “o gesto é, neste sentido, comunicação de uma comunicabilidade".

Essa ideia paradoxal de "meio sem fim" é a pedra de toque a provocar a ruína de um modo de pensamento teleológico que produz e organiza, em larga medida, as vidas contemporâneas. Sequestrando-se o conforto da linearidade pressuposta no jogo lógico entre meios e fins, o gesto, rompendo tal linearidade, colocaria em suspensão, também, a necessidade de evocar a contrapartida do sentido para compreendê-lo, abordá-lo, tomá-lo, interpretá-lo, decifrá-lo.

Para realizarmos esse giro em relação à questão do gesto, faz-se necessário refutar uma abordagem da linguagem alicerçada num tratamento hermenêutico, interpretativo, tendo em vista a compreensão dos supostos sentidos que lhe seriam subjacentes. Ao contrário, na medida em que gesto comunicaria tão somente sua própria ação de comunicabilidade de um puro meio, faz-se necessário tomá-lo a partir de uma frente analítica que assuma a linguagem em sua força eminentemente performativa. Gesto constitui-se, pois, como pura performance, puro assumir, puro sustentar. Sua efetividade não se encontraria nos sentidos do dizer, mas no próprio acontecimento do indizível desse ato assim presentificado.

Afirmamos, pois, que haveria, no gesto, uma potência do intransitivo. Dado que o gesto não resguardaria a polissemia de segredos em vias de decifração, instaura-se uma fecunda intransitividade hermenêutica, ou seja, um embotamento 
no fluxo compreensivo. Porém tal intransitividade não equivale ao flerte com o sublime, tal como sugerido pelo romantismo estético. Trata-se de uma intransitividade como gesto mesmo: a presença inarredável do impasse, do vazio como uma ocupação plena do tempo, dispararia movimentos insuspeitos e faria saltar efeitos outros, reconfigurando indefinidamente o jogo cartográfico, tal como sugerido por Gilles Deleuze e Félix Guattari (1995).

Apostamos que a dilatação analítica da experiência do gesto irrompe como um recurso extremamente potente para enfrentarmos demandas de ordem ética e política. Apostamos também que o horizonte desse salto possível pode se constituir num dos modos intensivos de nos lançarmos ao embate com o pensável da cultura contemporânea, uma vez, que, como já sinalizado por Agamben (2008, p. 12), "o gesto abre a esfera do ethos".

\section{Das urgências cartográficas}

Ao telefone com o irmão, Jeanne diz:

Mas para isso é primeiro ela, é a mamãe que eu tenho que encontrar, na sua vida de antes, nessa que durante todos esses anos ela escondeu da gente. Vou desligar, Simon. Vou desligar e mergulhar de cabeça, mergulhar longe, muito longe dessa geometria precisa que estruturava minha vida. Aprendi a escrever e a contar, a ler e a falar. Tudo isso não serve para mais nada. $\mathrm{O}$ abismo no qual vou me enfiar, esse para dentro do qual já estou escorregando, é o abismo do silêncio dela. (MOUAWAD, 2013, p. 77-78)

Nawal, a mãe, sustém, em gesto, a radicalidade do silêncio. Enquanto o filho Simon recusa a imersão no abismo de sentidos supostamente entranhados nesse silenciar, Jeanne, sua irmã, é dragada pela ocupação desse vazio intransitivo, habitando-o. Refratário aos imperativos de forma e de conteúdo, tal vazio se instala como pura presença.

Ocorre, pois, uma torção fundamental: Jeanne, essa linha de passagem, parece ultrapassar a demanda hermenêutica de povoar de ruídos o gesto de silêncio de Nawal. Esvaziando a pergunta imediata sobre o sentido, ou mais especificamente, sobre aquilo que substancializaria a verdade, diríamos que Jeanne faz circular outra convocação, a qual resiste a esse clamor caro à cultura, o qual 
busca arrebatar a vida a partir de segmentações lineares entre começos, meios e fins. Trata-se de render-se à convocação do inexpressível.

Esse acontecimento no qual os sentidos já não bastam, sufocando-se, engasgando-se em seus cálculos impotentes, encontra no verbo de Agamben (2008) uma instigante enunciação:

[O gesto] não tem propriamente nada a dizer, porque aquilo que mostra é o ser-na-linguagem do homem como pura medialidade. Mas, assim como o ser-na-linguagem não é algo que possa ser dito em proposições, o gesto é, na sua essência, sempre gesto de não se entender na linguagem, é sempre gag no significado próprio do termo, que indica, antes de tudo, algo que se coloca na boca para impedir a palavra. (AGAMBEN, 2008, p. 14 , grifo do autor)

Ora, se o gesto diz de sua própria ação de dizer, sua condição muda parece ser essencial à sua potência. É desse abismo que se trata. $\mathrm{O}$ mergulho de Jeanne não responde a um apelo subjetivo da mãe ou de si, ativado por um silêncio factual. Trata-se de abrir passagem ao mutismo inerente ao gesto mesmo que, afirmado, coloca em questão absoluta certa geometria do viver.

Se gesto é esse gag da linguagem, esse "algo que se coloca na boca para impedir a palavra" (AGAMBEN, 2008, p.14), como acima formulado pelo pensador italiano, tende a acionar outras modulações nos regimes de percepção, situação que nos permite pensar em outras políticas da atenção - demandas urgentes na ambiência contemporânea.

$\mathrm{Na}$ contramão das velocidades atuais, com suas vertigens, o mutismo faz dilatar a temporalidade, tornando intensivo o presente, exigindo dos homens outros silêncios - esses agudos gestos de espera que atuam como outros verbos, uma vez que aqueles canônicos já não podem mais geometrizar.

Insistimos que não é exatamente a busca da verdade da origem o que move, por sua vez, esse gesto-Jeanne. Já se sabe de largada sobre a verdade oculta: alhures, há um pai, há um irmão. Mas há um mutismo essencial que exige outro gesto: a espera. Mergulhando num tempo sem fim, em absoluta suspensão cronológica, "Jeanne coloca os fones de ouvido, insere uma nova fita cassete e volta a escutar o silêncio da mãe dela" (MOUAWAD, 2013, p. 78). 
O acontecimento mudo requer a invenção de outra modalidade de atenção, gesto de resistência, portanto, frente à temporalidade avassaladora das formas culturais mais imperiosas da atualidade.

Potente, essa linha Nawal-Jeanne resiste à obediência da série silênciodecifração e inventa uma gestualidade silêncio-espera. Nesse gesto outro que atravessa o campo imanente de todas as vidas em afetação é preciso a coragem de recusar a geometria, com seus cálculos de linhas e pontos, de tal maneira que se possa ensaiar uma cartografia de signos.

Há de se converter a atenção numa ética, numa política, de modo a cartografar a intensidade do tempo dilatado do presente. É nesse sentido que habitar a temporalidade da espera requer outra política de atenção, outra política de percepção.

Dispor-se à atenção e à percepção não são ações derivadas de supostas faculdades inerentes à condição humana. $\mathrm{O}$ pesquisador norte-americano Jonathan Crary (2013), em seu extenso estudo Suspensões da percepção, ancorado no pensamento de Michel Foucault e Gilles Deleuze, desnaturaliza tais ações, reconstruindo, por meio de uma genealogia da atenção, os processos históricos que a tornaram centrais ou não na produção das subjetividades e formas de vida, desde a modernidade até a contemporaneidade.

Crary (2013, p. 32) aponta o movimento duplo aí presente:

as raízes da palavra atenção ecoam um sentido de "tensão", de estar "estirado", e também de "espera". Ela sugere a possibilidade de fixação, de manter-se em estado de fascinação e contemplação por alguma coisa no qual o sujeito atento está imóvel e ao mesmo tempo desancorado.

Em nossa argumentação, a exploração desses movimentos da atenção nos parece crucial para abordarmos sua envergadura ético-política nos jogos de forças produtores de formas de vida. A partir dessa interpelação genealógica, Crary (2013, p. 36) afirma:

Seria possível dizer que um aspecto crucial da modernidade é uma crise contínua da atenção, na qual as configurações variáveis do capitalismo impulsionaram a atenção e a distração a novos limites e limiares, com a introdução ininterrupta de novos produtos, novas fontes de estímulo e fluxos de informação, respondendo em seguida com novos métodos para administrar e regular a percepção. 
Assim, alinhados com o autor, afirmamos que se faz necessário considerar que os regimes de atenção e de percepção são efeitos das condições de necessidade e de contingência históricas. Delineiam-se, pois, modos de produção dessas experiências que investem, sobretudo na produção de temporalidades oportunas à vigência de certas malhas discursivas. Para isso, modular capturas da atenção e fomentar designs de percepção operam como dispositivos fundamentais seja na produção de subjetividades ou de estratégias de controle de formas de vida.

Seria possível, a partir desse horizonte, defendermos que a força ativada no campo relacional a partir da linha Nawal-Jeanne empreende uma luta contra os regimes de atenção e de percepção imperativos no contemporâneo daquelas vidas. Eis o gesto impessoal de natureza ética e política, portanto.

Empreitar esse gesto só parece ser possível porque foi recusada uma ordem geométrica, engendrando-se, tragicamente, uma experiência cartográfica então atiçada pela convocação dos novos signos que inundaram o tempo presente. Em suma, trata-se de saltar de uma geometria para uma cartografia.

É na companhia de Gilles Deleuze (1997, 2006, 2007, 2010, 2016) e Gilles Deleuze e Félix Guattari $(1992,1995)$ que propomos acompanhar esse movimento. Diríamos que pensar estilização e politização de um gesto supõe tomá-lo como um trabalho cartográfico com signos. Daí a relevância na criação de outra economia da atenção, de outro jogo de percepção.

O que se chama "percepção" não é mais um estado de coisas, mas um estado do corpo enquanto induzido por um outro corpo, e "afecção" é a passagem deste estado a um outro, como aumento ou diminuição do potencial-potência, sob a ação de outros corpos. (DELEUZE; GUATTARI, 1992, p. 199)

Para os pensadores franceses, tomar os signos implica apreender um jogo de afecção. A discussão implica uma atenção ao movimento, uma vez que, para eles, “os signos não são signos de alguma coisa, mas são signos de desterritorialização e reterritorialização e marcam um certo limiar transposto nesses movimentos" (DELEUZE; GUATTARI, 1995, p.85).

Assim, Incêndios sugere, a partir dessa linha Nawal-Jeanne, o disparo de um jogo de afecção que ultrapassaria uma jornada de caráter hermenêutico, a qual 
tenderia a perseguir o sentido dos gestos e a fazer falar um enigma de silêncio. Trata-se de outra empreitada: apreender Nawal como uma linha que dá passagem a uma modalidade incorpórea de herança, aquilo que poderíamos chamar de um aprendizado. Aprende-se, no encontro com o gesto, uma cartografia de signos capazes de provocar criação de pensamento.

Essa viagem cartográfica implica menos um deslocar-se para uma verdade da origem, de um tempo passado, e mais uma espécie de nomadismo no próprio presente. A atenção à dilatação do presente passa a ser, portanto, um gesto éticopolítico de resistência, gesto eminentemente mudo, herdado e aprendido.

Enfrentar a virtual tragicidade que vai materializando a atmosfera do presente requer uma recusa à busca de similitudes e uma entrega à indiscernibilidade. Para Deleuze (1997, p. 90) uma zona de indiscernibilidade "se estabelece entre dois termos, como se eles tivessem atingido o ponto que precede imediatamente sua respectiva diferenciação: não uma similitude, mas um deslizamento, uma vizinhança extrema, uma contiguidade absoluta".

Essa imagem de "uma vizinhança extrema, uma contiguidade absoluta" é fulcral - trata-se de um esforço analítico para instaurar esse lugar limite no qual tudo está por um triz: na insistência dos espelhamentos que nos replicam uma ordem do mundo à exaustão, também nos arrastam as voragens dos signos anunciando o tom vibrátil da diferenciação.

Ao tomar a obra de Marcel Proust para evocar essa condição de afecção dos signos, ou seja, essa potência do indiscernível, Deleuze constrói uma bela imagem:

Eu creio que o narrador [de Em busca do tempo perdido] tem um método e que não o sabe a princípio, que o aprende em diferentes ritmos, em ocasiões muito distintas, e que este método é literalmente a estratégia da aranha. [...] A aranha crê, porém crê unicamente nas vibrações de sua teia. Enquanto a mosca não entra em sua teia, a aranha não crê em absoluto na existência da mosca. Não crê. Não crê nas moscas. Pelo contrário, crê em qualquer movimento da teia, por minúsculo que seja, e crê nele como se fosse uma mosca, ainda que seja outra coisa. (DELEUZE, 2007, p. 61-64, tradução nossa)

Essa disposição à afecção parece ser aquilo que possibilita uma criação cartográfica da existência, esse gesto não pessoal, que implica a politização e estilização das vidas. Crer "em qualquer movimento da teia, por minúsculo que 
seja", disponibilizar-se aos seus encontros, materializá-los como afectos - eis o aprendizado, cujo fim não se encontra para além dali, num resgate ao passado inconfessável, mas no próprio gesto de nomadizar o tempo, vertendo-o em sua mesma direção, intensificando-o, pois.

A atenção à plenitude dos sinais do tempo presente é um gesto radical de pensamento e portanto, do viver. Retomando um argumento dos estoicos, Deleuze afirma que:

todo signo é signo de um presente. [...] passado e futuro são precisamente apenas dimensões do próprio presente (a cicatriz é o signo, não da ferida passada, mas do "fato presente de ter havido uma ferida": digamos que ela é contemplação da ferida, ela contrai todos os instantes que dela me separam num presente vivo). (DELEUZE, 2006, p. 121)

Essa intensificação do presente, tomado como um lugar de contração de todas as forças do tempo e, portanto, ocasião inexorável de afirmação trágica, torna-se, nessa entrega cartográfica aos encontros com os signos, um acontecimento.

Entretanto, essa dimensão de encontro não se resolve dialogicamente, sob uma economia de correspondência de afectos. Ao contrário: aqui, o aprendizado se faz na coragem de recusa ao jogo de recognição da cultura. Sem eufemismos, é de um modo de violência que trata Deleuze:

Sem algo que force a pensar, sem algo que violente o pensamento, este
nada significa. Mais importante do que o pensamento é o que "dá que
pensar". [...] O que nos força a pensar é o signo. O signo é o objeto de um
encontro; mas é precisamente a contingência do encontro que garante a
necessidade daquilo que ele faz pensar. O ato de pensar não decorre de
uma simples possibilidade natural; é, ao contrário, a única criação
verdadeira. (DELEUZE, 2010, p.89-91) Um jogo, quando fundado na prerrogativa de compartilhamento de sentidos entre os homens, sequestra da presença do signo sua potência de afecção. Diferentemente, nessa perspectiva Deleuze-guattariana, o ato de pensamento seria de ordem agonística e não de natureza compreensiva.

Essa atenção cartográfica exige uma predisposição ao encontro divergente com o signo, nocauteando-se assim os pressupostos de recognição, ultrapassando o campo do reconhecível e acionando uma experiência de indiscernibilidade. Nessa deambulação, provoca Deleuze (2006, p. 210) “não são os deuses que são 
encontrados; mesmo ocultos, os deuses não passam de formas para a recognição. $\mathrm{O}$ que é encontrado são os demônios, potências do salto, do intervalo, do intensivo ou do instante; eles são os porta-signos".

\section{Dos demônios na infância do mundo}

Nawal, 65 anos, escreve em sua carta-testamento aos filhos: "gravem o meu nome sobre a pedra e coloquem a pedra sobre meu túmulo" (MOUAWAD, 2013, p.132).

Nawal, 16 anos, ouve de sua avó:

Escuta o que uma velha mulher que vai morrer tem para te dizer: aprende a ler, aprende a escrever, aprende a contar, aprende a falar. Aprende. [...] Você, Nawal, quando você souber, volta e grava meu nome sobre a pedra: "Nazira". Grava meu nome pois eu cumpri as minhas promessas. (MOUAWAD, 2013, p.48)

Cunhar o nome na pedra do túmulo - eis o espírito dessa jornada. Para tal gesto, faz-se necessário ultrapassar o mero saber acerca da origem. Trata-se, na acepção agambeniana de gesto, de sustentar a historicidade desse saber de modo a inscrever uma assinatura no mundo.

Quando o presente se afirma como lugar intensivo de signos em seus jogos de afecções e seus demônios indiscerníveis, rompe-se a temporalidade linear que, ao sitiar a vida em polos, redunda num esforço pueril de recognição de origens e fins. Resistindo contra essa vontade sôfrega de esclarecimentos perante o viver, o espírito nietzschiano em Deleuze relembra: "é a vida que justifica, ela não precisa ser justificada".

Essa também poderia ser a epígrafe de Incêndios, uma vez que já não basta o trabalho de esclarecimento ou de conhecimento de uma verdade, mas a estilística de um o gesto capaz de sustentar a vida mesma, naquilo que ela forja.

Assim, a insistência de Mouawad (2013, p. 130) no mantra "a infância é uma faca enfiada no pescoço" é uma marcação rítmica que emula o gesto de Nawal, incitando-a a corromper uma historicidade crivada por lugares estruturais previamente demarcados numa sequência temporal. 
Num giro ousado, infância e morte emergem num só engendramento e retornam num tempo circular, violentando assim a ambiência de nosso pensamento contemporâneo, e por isso mesmo, nos movendo em outra direção, incognoscível, indiscernível. A verdade da infância, antes signo da origem considerando a placidez de um mundo ordenado pela recognição - passa a valer, agora, tão somente, como uma das contingências possíveis, uma verdade qualquer. Eis o desafio desse deslocamento radical, o qual arranca sua força da afirmação do trágico.

Recusando a oferta fácil de mera revelação de um saber, Nawal é materialidade do gesto mesmo de uma convocação cartográfica ao viver. Desloca o problema da verdade da origem para abrir passagem a outro raio de interpelação, disparado por um chamamento ético-político: como sustentar a vida, no inominável de sua força manifesta, a despeito de uma genealogia do ódio e seus efeitos?

Ainda que a agonística dos traçados genealógicos não ofereça trégua ao pensamento ou ao viver, urge forjar uma política outra de atenção capaz de fazer proliferar uma expansão de signos, em sua planície rizomática. Se “o rizoma é uma antigenealogia", como afirmam Deleuze e Guattari (1995, p.32), uma interpelação cartográfica aciona, aqui, um instrumento de guerra para enfrentar o contínuo movimento do mundo, com suas temporalidades lineares e suas formas de vida indolentes.

Nesse sentido, o mantra que insiste nessa injunção entre infância e morte faz lembrar da permanente dança de circularidade que nos constitui. Tal movimento liberta a infância de uma localidade estrutural, como marcação de um começo. Infância torna-se ubiquidade, onipresença, condição que nos possibilita experienciá-la não mais como um tempo de origem, mas como um tempo qualquer. Movente, a origem estaria em qualquer tempo, em toda parte. No eterno retorno desse tempo qualquer, insurreto a quaisquer teleologias, saltam as tais potências demoníacas, em trabalho de experimentação. 
"Ir em direção à infância do mundo" - conclama Deleuze (2016, p.31). Parece-nos que esse clamor busca acionar a força de um tempo no interior do tempo que poderia, em sua intensidade, re-presentificar a vida. Arredia a toda substancialização, infância, essa força pervasiva, ativaria a própria atualização do presente, abrindo-lhe o espectro de multiplicidades (im)possíveis.

Essa incursão à infância do mundo implica adentrar a indiscernibilidade desse tempo qualquer, suspender as bússolas dos deuses, contagiar-se pelo furor dos demônios.

Dessa infância qualquer Nazira-Nawal-Jeanne, que eternamente retorna em nós, um aprendizado: fazer do gesto de atenção, uma política; fazer da investida cartográfica do viver, uma ética.

Se, como afirma Agamben (2008, p.14), “a política é a esfera dos puros meios, isto é, da absoluta e integral gestualidade dos homens", parece ser este o gesto testamentário legado ao contemporâneo: a construção da dignidade necessária à assinatura do mundo. E assinar o mundo não é gesto autoral: é a potência mesma da vida quem assina em nós.

\section{Referências}

AGAMBEN, Giorgio. Notas sobre o gesto. Artefilosofia, Ouro Preto, n. 4, p. 9-14, jan. 2008.

CRARY, Jonathan. Suspensões da percepção: atenção, espetáculo e cultura moderna. São Paulo: Cosac Naify, 2013.

DELEUZE, Gilles. Crítica e clínica. Rio de Janeiro: Ed. 34, 1997.

. Diferença e repetição. 2a . ed. Rio de Janeiro: Graal, 2006.

Mesa redonda sobre Proust. In: Dos regímenes de locos: textos y

entrevistas. Valencia: Pre-textos, 2007. p. 51-70.

Proust e os signos. Rio de Janeiro: Forense Universitária, 2010.

. O abecedário de Gilles Deleuze. Disponível em:

http://stoa.usp.br/prodsubjeduc/files/262/1015/ Abecedario+G.+Deleuze.pdf. Acesso em: 06 jun. 2016. 
uma infância, um silêncio, um aprendizado do gesto

DELEUZE, Gilles; GUATTARI, Félix. O que é filosofia? Rio de Janeiro: Ed. 34, 1992. . Mil platôs: capitalismo e esquizofrenia - volume 1. Rio de Janeiro: Ed. 34, 1995.

GALARD, Jean. A beleza do gesto: uma estética das condutas. São Paulo: EDUSP, 1997.

MOUAWAD, Wajdi. Incêndios. Rio de Janeiro: Cobogó, 2013.

Recebido em: 15.05.2016

Aceito em: 20.06.2016 